\title{
O CORPO DAS MULHERES, LUGAR DE ENTENDIMENTO ENTRE O ISLÃ E O CRISTIANISMO NA NIGÉRIA*
}

\author{
Charmaine Pereira \\ Jibrin Ibrahim
}

\section{RESUMO}

Este artigo explora os fundamentos ideológicos comuns do islã e do cristianismo na Nigéria em matéria de gênero e sexualidade. $O$ corpo das mulheres constitui um elemento-chave na definição das normas sociais e das práticas de tal ou qual confissão. Examinaremos aqui a interação entre religião e política através de um contexto histórico e de exemplos concretos. Para a direita religiosa, muçulmana ou cristã, o corpo das mulheres é fator de devassidão e deve ser controlado - ponto de vista compartilhado por certas instituições laicas. A correlação entre corpo das mulheres e 'moral pública' gera diversas formas de desigualdade entre os sexos, cujas consequências econômicas complicam a luta contra a instrumentalização política da religião e contra a sexualização do político.

Palavras-chave: Nigéria. Religião e Política. Islã. Cristianismo. Corpo. Sexualidade. Violências. Moral.

\section{LE CORPS DES FEMMES, TERRAIN D'ENTENTE DE L'ISLAM ET DU CHRISTIANISME AU NIGERIA}

\section{RÉSUMÉ}

Cet article explore les fondements idéologiques communs de l'islam et du christianisme au Nigeria en matière de genre et de sexualité. Le corps des femmes constitue un élément clé dans la définition des normes sociales et des pratiques de telle ou telle confession. On examinera ici l'interaction entre religion et politique au travers d'um contexte historique et d'exemples concrets. Pour la droite religieuse, musulmane ou chrétienne, le corps des femmes est facteur

* Traduzido da versão francesa para o português por Etienne Alfred Higuet. O texto original em francês, "Le corps des femmes, terrain d'entente de l'islam et du christianisme au Nigeria", Cahiers du Genre, 2012/3 (HS nº 3), p. 89-108, foi traduzido do inglês por Jacqueline Heinen. 
de débauche et doit être contrôlé — point de vue que partagent certaines institutions laïques. La corrélation entre corps des femmes et 'morale publique' engendre diverses formes d'inégalité des sexes, dont les retombées économiques compliquent la lutte contre l'instrumentalisation politique de la religion et contre la sexuation du politique.

Mots-clés: Nigeria. Religion et Politique. Islam. Christianisme. Corps. Sexualité. Violences. Morale.

O Islã e o Cristianismo são geralmente apresentados em termos conflitivos na Nigéria. Isso não tem nada de estranho, tendo em vista a rivalidade histórica entre as duas confissões e a série de conflitos desastrosos, com influência religiosa, nas diversas partes do país, em particular durante os períodos de transição política (Ibrahim, 1991). Admite-se, todavia, menos frequentemente a sua convergência no plano ideológico. Ela tornou-se possível pelo fato da religião constituir um espaço privilegiado para a construção do gênero e da sexualidade, além dos pontos comuns ou da distância entre os discursos dos diversos cultos. Apesar das mulheres formarem um grupo muito heterogéneo na Nigéria, não apenas pela origem étnica e religiosa, mas pela idade, o estatuto matrimonial ou a região, o seu corpo oferece um lugar privilegiado para definir as normas e as práticas sociais. O corpo, de fato, não é uma entidade 'natural' ou neutra, desprovida de marcas históricas ou culturais: ele está sempre mais ou menos sob a influência de pressões sociais (Grosz, 1994).

O papel imposto às mulheres na transmissão da cultura, da religião e da tradição no conjunto do continente africano (Mama, 1997) comporta assim um forte alcance simbólico. Mohanram afirma:

O corpo da mulher permite aos cidadãos machos se familiarizarem com [...] a dimensão reconfortante e familiar da [...] nação (1999, p. 83).

Na mesma linha, pode-se dizer que o corpo das mulheres é um vetor-chave das práticas religiosas, visto a importância que reveste na definição do gênero e da sexualidade. O uso do véu (ou sua ausência) é um exemplo flagrante, já que permite, na Nigéria, distinguir as mu- 
çulmanas das cristãs ou das adeptas de cultos tradicionais. Ele marca o corpo de tal modo que designa o gênero e, muitas vezes, a identidade religiosa, e, ao mesmo tempo, mascara a sexualidade.

O discurso religioso, no Cristianismo assim como no Islã, considera as pulsões sexuais como naturais e as canaliza para o casamento e a reprodução, enquanto estigmatiza a homossexualidade e as relações sexuais fora do casamento. Na diferença do Cristianismo, que associa a sexualidade ao pecado e procura afastar dela as mulheres (Nelson, 1987), o Islã não nega a sexualidade delas, mas a apresenta como mais agressiva e perigosa que a dos homens, motivo pelo qual importa controlá-la (Imam, 2000; Mernissi, 2001). Aos olhos das crenças tradicionais africanas, as mulheres possuem poderes sexuais capazes de subverter os homens e submeter as mulheres. Numerosas práticas costumeiras visam a explorar essa aptidão, reforçando, ao mesmo tempo, a subordinação social das mulheres (Osakue, Martin-Hilber, 1998).

No contexto nigeriano, a religião foi amplamente politizada com fins oportunistas, como se verá em seguida. O campo da moral e, sobretudo, da imoralidade da sexualidade feminina, é um ponto comum da direita religiosa cristã e muçulmana deste país. Os casos evocados aqui esclarecem as similitudes e as diferenças no seu modo de abordar as questões de moralidade e de decência, e de justificar politicamente a vontade de controlar o corpo das mulheres e a sua sexualidade.

\section{PLURALISMO ÉTNICO E RELIGIOSO NA NIGÉRIA: UMA MISTURA PERNICIOSA}

A Nigéria representa uma das experiências democráticas mais importantes de governo federal no mundo. Com mais de cento e quarenta milhões de habitantes, o país abrange quase trezentos e cinquenta grupos étnicos, cujos três principais agrupam 60 \% da população total - os Haoussa no noroeste (28\%), os lorubas no sudoeste (18\%) e os Igbos no sudeste (14\%). As relações políticas neste país foram tortuosas, em razão de lutas pelo poder refletindo os blocos étnicos, religiosos e regionais. O Congresso do Povo do Norte (CPN) herdou o poder dos britânicos no momento da independência enquanto partido dominante, ao mesmo tempo, na região Norte e no nível federal. O grupo de 
ação Ioruba encabeçava a oposição que controlava a região Oeste. A região Leste era dominada pelos Igbos, por intermédio do seu partido - o Conselho Nacional da Nigéria e de Camarões (CNNC). O caráter explosivo da situação decorre da mistura problemática de poderosos partidos políticos étnico-regionais com dominante masculina, pesando, ao mesmo tempo, no sentido da luta pela independência e na prática do federalismo à nigeriana. Essa mistura está na origem das tensões e das tradições que marcaram a vida política deste país até agora.

A principal ameaça à existência da Nigéria enquanto país foi a guerra civil de 1967 a 1970, que provocou a perda de mais de um miIhão de vidas. Relações tensas no plano civil e comunal dominaram a primeira fase do federalismo nigeriano, de 1958 a 1965 . O poder real residia então nas regiões, mas a luta dizia respeito ao que se conveniou designar como o bolo nacional. Depois da guerra, as quatro regiões foram divididas em trinta e seis Estados pelos regimes sucessivos, em vista de favorecer a unidade nacional. Apesar disso, os conflitos étnicos e religiosos não deixaram de impregnar o devir político do país. No norte da Nigéria, uma série de conflitos sangrentos, de 1980 aos nossos dias, nasceu em parte de batalhas históricas que tinham levado os muçulmanos Haoussa e Fulani a atacar as minorias étnicas agora cristãs (outrora pagãs) para submetê-las e convertê-las (Gbadamosi, Ajayi, 1980; Kukah, 1989). O discurso religioso ficou tão politizado que as crises repetidas levaram a um risco de guerra civil e de dissolução do Estado nigeriano (Ludwar-Ene, 1991).

\section{A POLÍTICA DA RELIGIÃO NA NIGÉRIA}

Levando em conta a proporção importante e quase igual de muçulmanos e de cristãos na Nigéria, o desenvolvimento, tanto do Islã quanto do Cristianismo, dependeu da sua capacidade respectiva em converter os adeptos de crenças tradicionais (Gilliland, 1991). No Censo de 1931, $50 \%$ dos habitantes foram registrados como "pagãos". Essa proporção passou a 18,2 \% em 1963, os muçulmanos representando então 47 \% da população, e os cristãos 34\%. Hoje, quase ninguém se declara "pagão" e, já que nenhum Censo ulterior colocou a pergunta da pertença religiosa, não se sabe qual das duas religiões recrutou a maioria dos "pagãos" 
remanescentes. O importante é, todavia, que as proporções são quase idênticas, embora cada campo esteja pensando em deter a maioria.

O crescimento rápido do Cristianismo, que rivaliza hoje com o Islã, religião dominante no Norte desde o século $\mathrm{XV}$, tinha ulcerado os muçulmanos originários desta religião. Nos anos 1960, uma vasta campanha de islamização foi lançada para inverter o processo de cristianização iniciado pelo colonialismo - o Primeiro Ministro da época era originário do Norte. Mas ele foi assassinado em 1966 por oficiais cristãos Igbo, provocando, como reação, o massacre de julho de 1966, que visava a vingar os muçulmanos dos cristãos, principalmente Igbo, no norte da Nigéria. Isso colocou um fim a um ciclo de três anos de guerra civil. Nos anos 1970, o assassínio do chefe do Estado por atores majoritariamente cristãos da região central, assim como as purgações e a execução subsequentes de oficiais desta região, manteve a acumulação de rancor e de ódio. O advento da IV ${ }^{a}$ República, em 1999, propulsou ao poder um cristão do Sul, Olusegun Obasanjo, que governou oito anos seguidos - um intermédio de peso entre longos períodos de domínio do Norte.

O crescimento super-rápido de um poderoso movimento de renovação, tanto islâmico quanto cristão, constitui outra dimensão explosiva do cenário político atual na Nigéria - a religiosidade tendo assumido um aspecto muito mais manifesto nas duas últimas décadas. Além disso, os atores do mundo sagrado se tornaram muito habilidosos em defender e até impor o seu ponto de vista na agenda política do país. O Islã, assim como o Cristianismo, conhece divisões internas e se associou de modo complexo a outros elementos desta sociedade plural, como as crenças africanas tradicionais, a origem étnica, o regionalismo e o estatismo. Nota-se, além disso, a existência de uma tendência relativamente nova, na forma de lutas ecumênicas em grande escala, cristãos e muçulmanos intervindo em blocos organizados (Ibrahim, 1989, 1999). A proporção de membros do clero (pastores, mallams ${ }^{1}$, cheiks, reverendos, imams e profetas) não parou de crescer e a batalha pelo controle do espaço teológico não parou de se ampliar. A afirmação, por um dos grupos, da sua identidade religiosa e da sua liberdade é interpretada pelo outro como sinal de dominação, e a resistência que se segue gera um alto risco de conflito.

Na África do Oeste islâmica, pessoa formada nos estudos corânicos. 
Os muçulmanos, do seu lado, colocam o acento no que consideram como a dimensão cristã da laicidade. A sua principal preocupação diz respeito à natureza do Estado nigeriano e ao direito costumeiro: para eles, a distinção entre sagrado e profano é inaceitável e o quadro jurídico que deveria reger a sua vida é a Xaria. Eles reprovam, por outro lado, o que consideram como o domínio da cultura cristã, resultado da dominação colonial na Nigéria. São testemunhos disso: a designação do sábado e do domingo como feriados, ao passo que a sexta-feira, dia santo dos islâmicos, é um dia de trabalho normal; o uso do calendário cristão gregoriano na vida oficial; os uniformes não islâmicos das meninas na escola; a melodia cristã do hino nacional; a cruz cristã como símbolo dos estabelecimentos de saúde, etc.

Os cristãos, do seu lado, associam o domínio político dos muçulmanos à erosão da laicidade na Constituição nigeriana. Sua preocupação essencial diz respeito à islamização, que, aos seus olhos, ameaça o país, e à imposição da Xaria aos não muçulmanos, em particular aos cristãos de certas regiões do Norte com predominância muçulmana. Acresce-se a preocupação com a tradição de hegemonia política dos muçulmanos na história do país e no exército, desde a independência. O uso dos recursos estatais para subsidiar atividades islâmicas é outro motivo de preocupação, em particular a peregrinação anual a Meca, assim como a apropriação pelo governo das escolas missionárias, cuja maioria era de obediência cristã.

Durante os três últimos decênios, o Cristianismo e o Islã mudaram profundamente o rosto da Nigéria, os antigos movimentos religiosos sendo substituídos pelos novos, dos quais as correntes mais prósperas são os Irmãos Muçulmanos (xiitas) e os Izala (wahabitas) para o Islã (Umar, 1993), e os pentecostais para o Cristianismo (Ojo, 1986). Se dirigindo, antes de tudo, aos indivíduos jovens ou em via de ascensão social, eles constituem um imenso exército de militantes muito ativos.

Hoje, na Nigéria, o Cristianismo, e principalmente o pentecostalismo, apresenta traços singulares, muito influentes (Ibeanu, 2006). Desde a sua eleição como presidente na ocasião da passagem do regime militar para um regime civil, em 1999, Olusegun Obasanjo nomeou numerosos funcionários pentecostais no governo e liberou os rituais 
dessa tendência religiosa em cerimônias públicas durante o seu mandato. Isso pesou fortemente na cultura política e contribuiu amplamente para a influência da direita religiosa cristã na sociedade. Hoje, os/as pentecostais dominam o setor das mídias eletrônicas, e igrejas carismáticas nasceram de uma renovação da fé nos campi universitários, nos anos 1970. Elas agrupam jovens instruídos/as, extremamente móveis, preocupados/as em modernizar as relações sociais, e cujo domínio do inglês lhes permite conectar-se facilmente à arena mundial dos meios de comunicação (Ojo, 2006).

Uma das principais razões do sucesso do pentecostalismo na África reside na sua capacidade de integrar os discursos e as práticas culturais das crenças africanas tradicionais, como o modo de superar as forças destruidoras do mal (Marshall-Fratani, 1998), prometendo, ao mesmo tempo, "a saúde e a riqueza", uma facilidade de acesso ao emprego, a contratos e serviços sociais. O pentecostalismo "foi um instrumento ideológico maior para o pensamento econômico (neo) liberal e a promoção do capitalismo" (Ibrahim, 2006, p. 15). Sua concepção das relações de gênero contribui, por outro lado, à manutenção e ao reforço das estruturas de poder na sociedade (Kalu, 2008), como ressaltaram críticas dirigidas a esta corrente. $O$ reconforto que a frequentação da igreja providencia às mulheres é qualificado de efémero e sem perspectiva de melhoria social: quase todos os grupos pentecostais fazem uma leitura literal da Bíblia, que usam para acentuar o domínio masculino. Os papéis reservados para as mulheres são cuidadosamente escolhidos para reproduzir as funções maternas e educativas tradicionais (ibid.). Por esse fato, o pentecostalismo contribuiu amplamente para consolidar não apenas o pensamento neoliberal, mas as desigualdades de sexo.

\section{RELAÇÃO ENTRE ESTADO E RELIGIÃO}

Tanto a Constituição de 1979, quanto a de 1999, tratam da relação entre Estado e religião, ao afirmar:

O governo da Federação ou de um Estado não deve adotar nenhuma religião como religião de Estado. 
Para os/as cristãos/ãs, essa cláusula significa que o país é laico, posição rejeitada pelos/as muçulmanos/as, já que o termo evoca, aos olhos deles/as, um vínculo com o Ocidente e uma orientação antirreligiosa.

A inclusão do direito penal na Xaria se fez no exato momento em que a elite muçulmana do Norte não controlava mais o governo federal e que o resto do país aspirava a uma mudança de poder, que impediria um muçulmano do Norte de tornar-se o próximo presidente. A extensão do campo de aplicação da Xaria nos Estados do Norte resultou provavelmente de um conjunto de temores: medo do processo de ocidentalização e mundialização, de um lado, e medo do domínio do Sul, do outro lado (Ibrahim, 2005). Durante o domínio colonial, o Sul, que não era regido pelo sistema da Xaria, tinha conseguido grande parte dos empregos na função pública e no comércio internacional. O seu peso nos setores modernos da economia era considerável. O Norte, por sua vez, contava com uma coesão política e uma numerosa população, e tinha conquistado o poder político central durante a $1^{\text {a }}$ República. A luta que ele conduzia a respeito da Xaria visava então a pesar na formação do Estado, para contrapor a influência do Sul na economia e na burocracia (Laitin, 1982).

Em princípio, a forte ampliação da Xaria poderia ter atingido diversos campos do desenvolvimento econômico e social. Na prática, no conjunto dos doze Estados submetidos à sua influência, o acento foi colocado sobre as penas ligadas a infrações tais como o roubo, a zina ${ }^{2}$ e o consumo de álcool, assim como a moralidade pública, através dos constrangimentos impostos às mulheres muçulmanas: injunção de vestir-se de modo apropriado, segregação completa em relação aos homens, restrições de movimento no espaço público (Sanusi, 2002a; Baobab, 2003). A focalização seletiva do novo código penal sobre as normas de moralidade pública provém da dominação da corrente wahabita (oriunda da Arábia Saudita), cuja interpretação do Islã é muito restritiva e punitiva.

A herança das práticas coloniais, que manipulavam a identidade étnica e religiosa para controlar os territórios do Norte, assim como

Toda forma de relação sexual consensual entre um homem e uma mulher não casados (em árabe). Os delitos são qualificados de fornicação ou adultério, conforme o estatuto conjugal. 
os efeitos mais recentes do programa de ajuste estrutural do Banco Mundial, contribuiu, tanto para as divisões sociais e econômicas, quanto para as desigualdades que favorecem o crescimento do extremismo religioso atual. $\mathrm{O}$ aparelho de Estado se mostrou incapaz de responder às necessidades sociais elementares em razão do pagamento da dívida e da redução dos orçamentos sociais. Não foi a pressão da renovação islâmica que levou à expansão inicial da Xaria, mas, antes, a ação oportunista de governadores desacreditados e corruptos. O uso político da Xaria foi bem-sucedido em razão do crédito que as pessoas em situação de precariedade concedem às injunções tradicionais: elas pensavam que a adoção e colocação em prática das leis penais islâmicas acabariam com a corrupção e acelerariam os procedimentos judiciais até então intermináveis (Imam, 2005).

\section{DEFESA DA 'MORALIDADE' E DA 'DECÊNCIA': O CONTROLE DO CORPO DAS MULHERES}

A insegurança da vida cotidiana atual na Nigéria provém da desordem social generalizada e das desigualdades geradas por uma economia dependente do petróleo, do enfraquecimento das instituições estatais, do crescimento da economia informal, e da ressurgência de conflitos étnicos e religiosos, paralelamente a múltiplos atos de violência criminal. Sanusi (2002b) ressalta que "os períodos de desintegração e incerteza favorecem as ideias totalitárias, na medida em que as pessoas aspiram à estabilidade". É impressionante que "o pentecostalismo e o islã, embora diferentes em muitos aspectos, tenham ambos um discurso moralizador a respeito da economia política, explicando as raízes da insegurança e propondo caminhos para combatê-la" (Larkin, 2008, p. 181).

Reencontramos dois elementos-chave, comuns aos diversos projetos de renovação: a instrumentalização do corpo das mulheres para marcar um território e definir um programa; e o recurso às leis - as que concernem à reprodução e a sexualidade, notadamente - para assegurar que as mulheres se dobrem perante as tarefas enunciadas. A delimitação das fronteiras é essencial "à criação de um inimigo digno desse nome" - no caso, o Ocidente decadente. O "principal símbolo dessa decadência, são as mulheres imorais e licenciosas" (Freedman, 
1996, p. 62). Em tempo de crise, as pessoas procuram responsáveis pela sua situação, e esses bodes expiatórios têm sido, de modo demasiado frequente, as mulheres. No fim dos anos 1970 e no começo dos anos 1980, houve esforços para controlar o seu vestuário e obrigar as solteiras a se casarem, acusando, ao mesmo tempo, as vendedoras nas feiras, de ter aumentado o preço dos produtos alimentares (Dennis, 1987; Pittin, 1991). Nos anos 1990, em Abuja, as mulheres frequentando as instituições estatais foram proibidas de usar calças. Incriminar as mulheres de estarem na origem da crise, sejam quais forem as razões dessa, é infelizmente uma prática velha como o mundo. Os exemplos que se seguem ilustram diversas maneiras dessas acusações tenderem a focalizar-se sobre o corpo das mulheres.

\section{A APLICAÇÃO DO NOVO CÓDIGO PENAL DA XARIA}

A aplicação do novo código penal atingiu, antes de tudo, pessoas de renda baixa e analfabetas, muitas vezes no campo, mas também da cidade - mulheres, homens e crianças. As acusações pronunciadas em relação às mulheres dizem respeito, o mais das vezes, a relações sexuais, tais como a zina. Em certos casos, as mulheres foram acusadas e declaradas culpadas de prostituição, sem nenhuma prova. Embora o indiciamento por fornicação, seguido pela pena do chicote, tenha atingido, ao mesmo tempo, homens e mulheres, apenas as últimas foram declaradas culpadas de adultério, crime passível da pena mais grave: a lapidação até a morte (Baobab, 2003).

As modalidades de aplicação das penas vinculadas ao novo código penal variam igualmente conforme o sexo: as mulheres solteiras devem provar a própria inocência, mas não os homens. A norma corânica, estipulando que quatro testemunhas oculares independentes devem ter observado o ato sexual para que uma alegação de zina possa ser formulada, é burlada na prática: se acusado, um homem apresenta quatro testemunhas declarando que ele não cometeu zina e sai livre, ao passo que uma mulher é condenada por fornicação ou adultério (ibid.).

O tratamento do estupro pelo código penal da Xaria é um exemplo límpido da desigualdade de gênero quanto à aplicação da lei. Sendo o estupro considerado uma forma de zina, denunciar um estupro equivale 
a confessar a zina. Para provar que houve estupro, é preciso que o estuprador tenha confessado o seu crime ou que duas testemunhas declarem ter assistido a ele. Ora, nenhuma dessas cláusulas tem chance de ser satisfeita. As mulheres que encaminham uma queixa por estupro perante um tribunal arriscam não apenas serem acusadas e punidas por zina, mas também por falso testemunho, em virtude da disposição conforme a qual toda pessoa que formula uma alegação de zina não confirmada será tida como culpada de falso testemunho e suscetível de sanções.

A sexualidade feminina é considerada cada vez mais como fonte de imoralidade (Imam, 2005). Na Nigéria do Norte, as práticas de transgressão sexual - sobretudo as relações heterossexuais fora do casamento - são diversas e fazem parte de costumes sexuais muito antigos. A aplicação do novo código penal resulta, todavia, em acusar principalmente as mulheres por esses crimes e em exercer uma total impunidade em relação aos homens (Pereira, 2005). De modo geral, a existência deste código reforçou o peso da direita religiosa muçulmana. No Estado de Zamfara, isso se traduz pela tentativa de obrigar as mulheres a sentarem na parte de trás dos veículos públicos e pela obrigação de respeitar o toque de recolher da meia noite em Gusau, a capital do Estado. As agressões contra as mulheres fora de suas casas e as visadas autoritárias para impor-lhes normas de vestuário são coisa comum. Muitas dessas práticas são cometidas por grupos ilegais de jovens vigias de sexo masculino, às vezes abertamente apoiados pelo governo, com é o caso nos Estados de Zamfara e Kano.

\section{OS UNIFORMES ESCOLARES NO COLÉGIO QUEEN AMINA DE KADUNA}

A questão de saber até que ponto o corpo feminino pode ser exposto ou deve ser velado foi objeto, conforme os momentos, de divergências, mas também de convergências de pontos de vista e de práticas entre muçulmanos e cristãos. Em julho de 1987, as normas de vestuário que se aplicam às meninas tornaram-se uma questão política explosiva quando estudantes cristãs e muçulmanas de um colégio feminino - o Queen Anima College de Kaduna - se enfrentaram a respeito dos uniformes escolares. A escola, que levava antigamente o nome de 
Queen of Apostles College, era comandada pela Igreja Católica até o momento em que o governo assumiu o controle de todas as escolas religiosas, nos anos 1970. Da mobilização crescente para afirmar a identidade muçulmana, nos anos 1980, nasceu a exigência de que os uniformes das meninas das antigas escolas cristãs, e até de todas as escolas, refletissem doravante a cultura muçulmana (Ibrahim, 1988).

Em março de 1987, graves levantes religiosos aconteceram no Estado de Kaduna, provocando a morte de centenas de pessoas. O conflito fora desencadeado por um motim entre cristãos/ãs e muçulmanos/as na ocasião de uma celebração cristã evangélica num colégio de Kafanchan. As jovens muçulmanas do colégio tinham se mobilizado a favor de uniformes muçulmanos, enquanto as alunas cristãs estavam se opondo. Face aos pedidos persistentes das muçulmanas e de seus/as pais/mães, e às pressões exercidas por responsáveis do ensino sobre o ministério de Estado de Kaduna, as colegiais muçulmanas receberam a permissão de usar um novo uniforme, composto por uma calça bufante e uma túnica de manga comprida até os joelhos (ibid.). Brigas estouraram no dia 14 de junho, quando algumas estudantes muçulmanas, desejando "ter uma aparência mais decente", resolveram vestir-se desse modo sem esperar o decreto oficial do Ministério. A escola fechou as portas durante duas semanas e o governo resolveu admitir os dois tipos de uniforme. Oito dias após a reabertura, contudo, um violente conflito estourou entre as estudantes; a polícia antimotim teve que intervir com gás lacrimogêneo para separá-las e muitas delas ficaram gravemente feridas. O Ministro Federal da Educação, Jubril Aminu, usou o acontecido como pretexto para mandar que os quarenta e um colégios federais do país fornecessem um segundo uniforme, composto por uma calça, uma camisa de manga comprida e um lenço (ibid.).

O conflito sobre os uniformes escolares no Colégio Queen Amina marcou uma virada na ocultação do corpo das mulheres, sob duas perspectivas essenciais. Antes disso, apenas as muçulmanas casadas precisavam usar véu. No fim do conflito, as jovens solteiras muçulmanas podiam vestir um uniforme escondendo eficazmente o seu corpo. Em segundo lugar, o fato da autorização aplicar-se ao nível secundário supunha a institucionalização deste tipo de traje no futuro. Foi possível 
constatá-lo indiretamente nos anos seguintes, quando uniformes do mesmo tipo apareceram na escola primária, e até mais cedo.

Essa batalha poderia parecer um incidente isolado, se não estivesse se apoiando num elemento importante: a ideia de decência do vestuário. Na medida em que se trata de uma construção religiosa, essa noção é diferente para os cristãos e para os muçulmanos. Afinal de contas, o conflito dizia respeito à questão de saber qual dos dois grupos religiosos levaria a melhor nesta ocasião. Além do antagonismo entre Islã e Cristianismo a respeito do novo código penal, existe traços ideológicos comuns absolutamente impressionantes: para um como para o outro, o corpo das mulheres é um fator de perturbação sexual, que importa controlar. Aliás, essa convicção impregna o pensamento e a prática laicos, tanto quanto religiosos. É nesse campo fértil que se iniciou a batalha atual a respeito da "indecência do modo feminino de se vestir".

\section{PROJETO DE LEI SOBRE A NUDEZ EM PÚBLICO E O ASSÉDIO SEXUAL}

No dia 9 de julho de 2008, uma sessão aberta ao público foi realizada na Assembleia Nacional sobre um Projeto de Lei "visando a proibir e punir a nudez em público, a intimidação sexual e outras infrações conexas na Nigéria". Numa apresentação anterior, o senador Eme Ekaette, promotor do projeto, se esforçara em apresentar o discurso da moral como idêntico ao da religião. Lembrando que a Constituição de 1999 evoca o povo da República Federal da Nigéria como "nação soberana submetida a Deus", e "povo [...] inteiramente submetido às leis do Todo-Poderoso", tentara demonstrar a legitimidade do último nos negócios da nação e no processo legislativo.

O próprio Projeto de Lei diz respeito à "nudez em público ou no exterior". Cinco das sete ocorrências sobre a conduta - dos/as indivíduos/as dos dois sexos - concernem unicamente às mulheres. A nudez em público é definida como "todo tipo de roupa indecente expondo (sic) [...] qualquer parte do corpo de dois polegares abaixo dos ombros e até o joelho de uma pessoa de sexo feminino com idade acima de 14 anos". A solução ao problema do modo indecente de se vestir (das muIheres) é criminalizar o último, o qualificando de "nudez em público". 
Na ocasião de uma transmissão da BBC do dia 12 de fevereiro de 2008, o senador Ekaette enunciou três motivos justificando as sanções penais para as mulheres "vestidas de modo indecente". O primeiro é que a "nudez em público" (das mulheres) é um sinal de costumes levianos. Trata-se de um argumento especioso resolvendo ignorar a rica história da exposição dos corpos nas sociedades africanas, que valoriza tanto a feminilidade quanto a masculinidade, a fecundidade e o charme. O segundo motivo é que a "moralidade pública” é um dos pontos sobre os quais a Constituição permite legiferar, já que os direitos fundamentais podem ser restringidos por leis "razoavelmente justificáveis numa sociedade democrática [...] no interesse da defesa, da segurança pública, da ordem pública, da moralidade pública ou da saúde pública”. O motivo mais alarmante usado pelo senador Ekaette para justificar o Projeto de Lei é, contudo, que o aumento contínuo do número de estupros na Nigéria seria devido à "provocação" ou aos "trajes indecentes" das mulheres. Admitir tal argumento equivale a absolver os estupradores de todo crime ou responsabilidade pelo seu delito. Os grupos de defesa dos direitos das mulheres que contestavam o Projeto de Lei objetaram que a responsabilidade pela "moralidade pública" não poderia recair apenas nas mulheres, pois, se fosse o caso, elas seriam penalizadas pela legislação.

O texto em questão define o "assédio sexual" como uma ação equivalente a um "pedido de relações sexuais com um homem ou uma mulher como condição para passar num exame, conseguir um emprego, um apoio da parte da empresa, obter um favor qualquer". O Projeto de Lei define, por outro lado, a "intimidação sexual" como "a exposição de uma parte privada do corpo humano [...] sob a forma de uma veste impudica [...] suscetível de seduzir uma terceira pessoa e de incita-la a pedir ou impor relações sexuais em troca de um favor". Em vez de proteger a vítima de assédio sexual, o Projeto de Lei autoriza, assim, o autor a pretender que ele foi "sexualmente seduzido" pelas "vestes indecentes" da mulher em questão! Levando em conta a propensão atual da polícia nigeriana e das forças de segurança em estuprar as mulheres de modo totalmente impune (Amnesty International, 2006; Noprin, 2007), o fato de promulgar tal lei favoreceria a escalada das 
agressões físicas, sob o pretexto de fazer respeitar os bons costumes. Pois, são os mesmos funcionários, quase todos homens, que estão em condições de agir após terem decidido se uma mulher está vestida decentemente ou não.

Isso coloca a questão de saber quem deveria estar com a razão na apreciação do que é um traje decente. O Projeto de Lei habilita atores não oficiais - as pessoas na rua, linchadores ou outros - a decretar por conta própria como as mulheres devem ser vestidas. Em Maiduguri, Grace Ushang, membro do Serviço da Juventude Nacional, foi estuprada pelos homens de uma gangue que, segundo o jornal NEXT (2009), "tinham achado uma ofensa o fato de ela usar a sua calça cáqui - uniforme oficial desta organização". Ela morreu em consequência dos seus ferimentos.

O Projeto de Lei sobre a nudez ainda não foi adotado, mas não está excluído que seja submetido à Assembleia Nacional, pois se beneficia do apoio da direita religiosa em nome da defesa da moralidade. Note-se que os considerando do texto são, ao mesmo tempo, fonte de convergências e divergências entre os/as cristãos/ãs e os/as muçulmanos/as que aderem a esta tendência. Uns/mas e outros/as estarão de acordo, ideologicamente, sobre a importância do traje das mulheres e a indecência em expor os seus corpos. Mas será por intermédio de atitudes e práticas definidas, segundo os casos, como religiosas, culturais ou ligadas à tradição.

A desigualdade de gênero está presente em praticamente todos os casos evocados aqui. Os corpos femininos são sexualizados de modo diferente que os dos homens: não há exemplo de conflito equivalente a respeito do uniforme escolar dos meninos, nem a vontade de controlar o traje dos homens no espaço público. A aplicação do novo código penal apoia-se, no essencial, sobre a existência de 'provas' criminais de zina, atestadas por uma gravidez, a qual torna as transgressões heterossexuais das mulheres, mais visíveis que as dos homens.

O importante, no caso, é a insistência geral sobre a moral e, em particular, sobre a 'imoralidade' da sexualidade e do desvelamento do 
corpo feminino. Notaremos que as angústias sociais provocam, muitas vezes, conflitos a respeito do comportamento sexual, ou "pânicos morais" (Rubin, 1984, p. 297). Contudo, os corpos das mulheres não estão intrinsecamente ligados à moralidade pública. A insistência nisso vem da insegurança crescente, da crise da economia e política na sociedade nigeriana. O desmoronamento geral da ordem social fica reduzido à imoralidade das mulheres e ao seu traje indecente. Tal abordagem constitui o tronco comum da direita religiosa cristã e muçulmana na Nigéria, e gerou um clima favorável à redução constante das liberdades das muIheres, à diminuição do acesso à justiça e à contestação em diversos planos da autonomia das mulheres.

Esses desenvolvimentos não deixaram de suscitar resistência organizada. Grupos de mulheres, de militantes dos direitos humanos, leia-se advogados e indivíduos lutaram pela defesa dos direitos das mulheres, sem levar sempre em conta as clivagens religiosas, lutando contra a aplicação do código penal da Xaria e contra o Projeto de Lei sobre a nudez pública. Atualmente, esses esforços se voltam antes de tudo para as normas e as práticas oficiais decorrendo do quadro jurídico. Entretanto, os efeitos indiretos da legislação são perniciosos e mais difíceis de serem contestados que as próprias leis. A moralização da economia política - consistindo em reduzir os múltiplos problemas sociais, políticos e econômicos ao controle do corpo das mulheres e aos 'bons costumes' é um problema complexo. É nesse campo que é preciso combater a politização da religião e as medidas geradas que decorrem dela, prosseguindo na luta pela igualdade dos sexos e pela justiça social.

\section{REFERÊNCIAS}

AMNESTY INTERNATIONAL. Rape: The Silent Weapon. London, Amnesty International, 2006

BAOBAB. Women's Human Rights Violations in Nigeria: 15 January 1966 - 29 May 1999. Research Report submitted to the Human Rights Violations Investigation Commission (Oputa Panel). Nigeria: Lagos, Baobab for Women's Human Rights, 2003.

DENNIS, Carolyne. Women and the State in Nigeria: The Case of the Federal Military Government 1984-85. In AFSHAR, Haleh (Ed.). Women, State and Ideology: Studies from Africa and Asia. London: Macmillan Press, 1987. 
FREEDMAN, Lynn. The Challenge of Fundamentalisms. Reproductive Health Matters, vol. 4, n 8, 1996.

GBADAMOSI, T., AJAYI, Jacob. Islam and Christianity in Nigeria. In: IKIME, Obaro (Ed.). Groundwork of Nigerian History. Ibadan: Heinemann, 1980.

GILLILAND, Dean. First Conversion and Second Conversion in Nigeria. Journal of Asian and African Studies, vol. 26, $n^{\circ}$ 3-4, 1991.

GROSZ, Elizabeth. Volatile Bodies: Towards a Corporeal Feminism. Bloomington: Indiana University Press, 1994.

IBEANU, Okechukwu. Christianity and Democratic Governance in Nigeria: An Explanatory Analysis. In: IBRAHIM, Jibrin (Ed.). Report on Christian Movements and Democratic Governance in Nigeria (A Research Project), vol. I. Report written for the Federal Government of Nigeria, 2006.

IBRAHIM, Jibrin. Les uniformes des lycéennes nigérianes. Politique Africaine, $n^{\circ}$ 29, 1988. IBRAHIM, Jibrin. The Politics of Religion in Nigeria: The Parameters of the 1987 Crisis in Kaduna State". Review of African Political Economy, vol. 16, n 45/46, 1989.

IBRAHIM, Jibrin. Religion and Political Turbulence in Nigeria. The Journal of Modern African Studies, vol. 29, n 1, 1991.

IBRAHIM, Jibrin. Ethno-Religious Mobilisation and the Sapping of Democracy in Nigeria. In: HYSLOP, Jonathan (Ed.). African Democracy in the Era of Globalisation. Johannesburg: Witwatersrand University Press, 1999.

IBRAHIM, Jibrin. Democracy, Religion and Minority Rights in Nigeria?. In: AHMED, Ishtiaq (Ed.). The Politics of Group Rights: The State and Multiculturalism. Lanham: University Press of America, 2005.

IBRAHIM, Jibrin. The Christianity Democracy Nexus in Nigeria. In: IBRAHIM, Jidrin (Ed.). Report on Christian Movements and Democratic Governance in Nigeria (A Research Project), vol I. Report written for the Federal Government of Nigeria, 2006.

IMAM, Ayesha. The Muslim Religious Right ('Fundamentalists') and Sexuality. In: ILKKARACAN, Pinar (Ed.). Women and Sexuality in Muslim Societies. Istanbul: Women for Women's Human Rights (WWHR) / Kadmin Insan Haklari Projesi (KIHP), 2000.

IMAM, Ayesha. Women's Reproductive and Sexual Rights and the Offence of Zina in Muslim Laws in Nigeria. In: CHAVKIN, Wendy, CHESLER, Ellen (Eds.). Where Human Rights Begin: Health, Sexuality and Women in the New Millennium. New Brunswick: Rutgers University Press, 2005.

KALU, Ogbu. African Pentecostalism: An Introduction. Oxford \& New York: Oxford University Press, 2008.

KUKAH, Mathew. Religion and Politics in Nigeria since 1960. Unpublished PhD thesis. University of London, 1989. 
LAITIN, David. The Sharia Debate and the Origins of Nigeria's Second Republic. The Journal of Modern African Studies, vol. 20, $\mathrm{n}^{\circ} 3,1982$.

LARKIN, Brian. Signal and Noise: Media, Infrastructure and Urban Culture in Nigeria. Durham: Duke University Press, 2008.

LUDWAR-ENE, Gudrun (Ed.). New Religious Movements and Society in Nigeria. Bayreuth University: African Studies, series n. 7, 1991.

Mama Amina. Shedding the Masks and Tearing the Veils: Cultural Studies for a Post-Colonial Africa. In: IMAM, Ayesha, SOW, Fatou, MAMA, Amina (Eds.). Engendering African Social Sciences. Dakar: CODESRIA, 1997.

MARSHALL-FRATANI, Ruth. Mediating the Global and Local in Nigerian Pentacostalism. Journal of Religion in Africa, vol. 28, $\mathrm{n}^{\circ}$ 3, 1998.

MERNISSI, Fatema. Scheherezade Goes West: Different Cultures, Different Harems. London \& New York, Washington Square Press: 2001.

MOHANRAM, Radhika. Black Body: Women, Colonialism and Space. Minneapolis: University of Minnesota Press \& St Leonards: Allen \& Unwin, 1999.

NELSON, Nici. 'Selling her Kiosk': Kikuyu Notions of Sexuality and Sex for Sale in Mathare Valley, Kenya”. In: CAPLAN, Pat (Ed.). The Cultural Construction of Sexuality. London \& New York, Routledge, 1987.

NEXT. "The Murder of Grace Ushang Adie", 1 October. 2009. Disponível em: < http://234next.com/csp/cms/sites/Next/Home/5470974-146/The_murder_of_Grace_ Ushang_Adie.csp >. Acesso em: 20 out. 2009.

NOPRIN. Criminal Force? An Interim Report on the NigeriaPolice Force Network on Police Reform in Nigeria. Lagos: NOPRIN, 2007.

OJO, Matthews. The Growth of Campus Christianity and Charismatic Movements in Western Nigeria. Unpublished PhD thesis, University of London, 1986.

OJO, Matthews. Typology of Christian Movements in Nigeria: An Overview. In: IBRAHIM, Jibrin (Ed.). Report on Christian Movements and Democratic Governance in Nigeria (A Research Project), vol I. Report written for the Federal Government of Nigeria, 2006.

OSAKUE, Grace, MARTIN-HILBER, Adriane. Women's Sexuality and Fertility in Nigeria: Breaking the Culture of Silence. In: PETCHESKY, Rosalind, JUDD, Karen (Eds.). Negotiating Reproductive Rights: Women's Perspectives across Countries and Cultures. London \& New York, Zed Books, 1998.

PEREIRA, Charmain. Zina and Transgressive Heterosexuality in Northern Nigeria. Feminist Africa, $n^{\circ}$ 5, 2005.

PITTIN, Renee. Women, Work and Ideology in Nigeria. Review of African Political Economy, n 52, 1991. 
RUBIN, Gayle. Thinking Sex: Notes for a Radical Theory of the Politics of Sexuality. In: VANCE, Carole S. (Ed.). Pleasure and Danger: Exploring Female Sexuality. Boston, Routledge \& Kegan Paul, 1984.

SANUSI, Sanusi Lamido. The Politicisation of Ontological Questions: Discourses, Subjectivities and Muslim Family Law in Nigeria. Comunicação apresentada na International Conference on Muslim Family Law in Sub-Saharan Africa, organizada pelo Centre for Contemporary Islam, University of Cape Town, South Africa, 11-14 de Março de 2002, $2002 a$.

SANUSI, Sanusi Lamido. The Hudood Punishments in Northern Nigeria: A Muslim Criticism. Preparado para publicação em ISIM News, a publicação quadrienal do Institute for the Study of Islam in Modernity. Leiden: Holland, 2002b.

UMAR, Muhammad. Changing Islamic Identity in Nigeria from the 1960 s to the 1980s: From Sufism to Anti-Sufism. In: BRENNER, Louis (Ed.). Muslim Identity and Social Change in Sub-Saharan Africa. London: Hurst, 1993. 